Review

\title{
Colorectal Cancer Screening in an Equal Access Healthcare System
}

\author{
Mia DeBarros, Scott R. Steele $\mathrm{e}^{凶}$ \\ Department of Surgery, Madigan Healthcare System, Tacoma, Washington, USA. \\ $\square$ Corresponding author: Scott R. Steele MD. Madigan Healthcare System, Department of Surgery, 9040a Fitzsimmons Dr, Tacoma, WA \\ 98431. Phone: 253-968-2200; Fax: 253-968-5337 Email: harkersteele@me.com \\ (c) Ivyspring International Publisher. This is an open-access article distributed under the terms of the Creative Commons License (http://creativecommons.org/ \\ licenses/by-nc-nd/3.0/). Reproduction is permitted for personal, noncommercial use, provided that the article is in whole, unmodified, and properly cited.
}

Received: 2013.01.15; Accepted: 2013.02.13; Published: 2013.03.20

\begin{abstract}
Introduction: The military health system (MHS) a unique setting to analyze implementation programs as well as outcomes for colorectal cancer (CRC). Here we look at the efficacy of different CRC screening methods, attributes and results within the MHS, and current barriers to increase compliance.

Materials and Methods: A literature search was conducted utilizing PubMed and the Cochrane library. Key-word combinations included colorectal cancer screening, racial disparity, risk factors, colorectal cancer, screening modalities, and randomized control trials. Directed searches were also performed of embedded references.

Results: Despite screening guidelines from several national organizations, extensive barriers to widespread screening remain, especially for minority populations. These barriers are diverse, ranging from education and access problems to personal beliefs. Screening rates in MHS have been reported to be generally higher at $71 \%$ compared to national averages of $50-65 \%$.

Conclusion: CRC screening can be highly effective at improving detection of both pre-malignant and early cancers. Improved patient education and directed efforts are needed to improve CRC screening both nationally and within the MHS.
\end{abstract}

Key words: colorectal cancer, screening, colonoscopy, military healthcare system, VA, flexible sigmoidoscopy, FOBT.

\section{Introduction}

Colorectal cancer (CRC) remains a major health care concern in the United States as well as globally. In 2009, it was the $2^{\text {nd }}$ leading cause of death for both men and women, accounting for an estimated 49,920 deaths ${ }^{1}$, in addition to being the $4^{\text {th }}$ leading cause of cancer -related death in the world ${ }^{2}$. Despite increased efforts in public education about CRC, more widespread availability of early detection methods, and improvements in treatment strategies, these numbers continue to be nearly identical. In fact, it is estimated that in 2012 alone 143,460 people (73,420 men and 70,040 women) will be newly diagnosed with colo- rectal cancer, along with an additional 51,690 deaths from this disease ${ }^{3}$. Apart from these profound medical aspects, CRC has far-reaching effects on the healthcare system as a whole. The medical and societal costs of colorectal cancer are substantial, with estimated direct medical costs for colorectal cancer in 2010 being $\$ 14$ billion, and projected costs of up to $\$ 20$ billion by $2020^{4}$. Furthermore, in 2006 the estimated lost productivity cost for people who died from CRC was $\$ 15.3$ billion, which translates to $\$ 288,468$ per person ${ }^{5}$. Conversely, while the cost of screening varies, it pales in comparison to those numbers, averag- 
ing only $\$ 71$ and $\$ 1,397$ per person for fecal occult blood testing (FOBT) and colonoscopy, respectively ${ }^{6}$. Considering that the pathogenesis of CRC occurs in a staged progression from normal mucosa to carcinoma over a period of 7-10 years, this length of time presents an excellent opportunity to utilize screening methods and detect lesions earlier, prior to the development of cancer ${ }^{9-11}$. Ultimately, the goal of reducing cancer deaths by removing these premalignant lesions and early-localized cancers can be instituted worldwide, resulting in a dramatic reduction in the incidence and mortality of CRC.

Despite this aim, screening for colorectal cancer still remains a significant challenge. On the positive side, a recent US population-based study shows that from 2002 to 2010 the percentage of persons aged 50-75 who were adequately screened for colorectal has increased from $52.3 \%$ to $65.4 \% 7$. On the downside, over $1 / 3^{\text {rd }}$ of people within this at-risk cohort still are never screened. Healthy People 2020 (HP 2020), a science-based 10-year national goal initiative for improving health, calls for reducing the incidence of CRC to 38.6 per 100,000 population, reducing the death rate to 14.5 per 100,000 population, and increasing the prevalence of CRC screening to $70.5 \% 13$. The causes for non-compliance are not surprisingly multi-factorial, and include physician unawareness, patient beliefs regarding CRC and screening, socio-economic status, and access to care. Each of these aspects, in some manner, makes the military health system (MHS) a unique setting to study implementation programs as well as outcomes. After all, MHS beneficiaries are an ethnically diverse population, encompassing people from all socioeconomic backgrounds, and each with the same opportunity for care. As with other malignancies, the MHS employs CRC screening based off of current national screening guidelines and has reported compliance rates up to $71 \%$. In this review, we will look at several issues surrounding colorectal cancer screening, including the efficacy of different CRC screening methods, attributes and results within the MHS, and current barriers to overcome in the future in order to increase compliance within the US population at large and increase the likelihood of meeting CRC screening goals.

\section{Current Modalities}

There are a variety of traditional screening methods available such as Fecal Occult Blood Testing (FOBT), Fecal Immunochemical Testing (FIT), Double Contrast Barium Enema (DCBE), Flexible Sigmoidoscopy (FS) and Colonoscopy (CS). In addition, newer methods such as CT Colonography (CTC) and fecal DNA testing aim to detect both premalignant and malignant lesions. FOBT is the most widely used method and has been studied in depth in several settings ${ }^{14-16}$. FOBT is used to detect the pseudoperoxidase activity of heme either as intact hemoglobin or free heme, although is not specific to human hemoglobin. FIT is similar to FOBT in collection method, yet it is able to detect human hemoglobin by utilizing reverse passive hemoglobin hemeagglutination. The assay uses fixed chicken erythrocytes coated with anti-human hemoglobin antibody. When these treated erythrocytes come into contact with human hemoglobin in fecal samples they agglutinate ${ }^{17}$. This makes FIT more specific than FOBT, but at the expense of sensitivity. It has been compared to FOBT (Hemoccult Sensa) in a number of studies with overall sensitivities ranging $70-94 \%$ (FIT) and 54-91\% (FOBT), respectively 18-22. Both FOBT and FIT primarily detect cancer, unlike endoscopy-based tests, which are classified as colon cancer prevention tests.

Overall, FIT has been evaluated in several studies. Petrilli et al found a positive predictive value of $7.3 \%$ and positive test rate of $4.9 \%$. St. John et al reported a sensitivity of $97.2 \%$ in 107 patients with known colorectal cancer and a sensitivity of $58 \%$ in 81 patients with polyps. The estimated specificity in 1355 screened patients was $97.8 \% 24$. Two studies evaluated the use of FIT in average risk patients. Robinson et al reported positive test rate of $9.7 \%$ and PPV of $6.2 \%$ for cancer. The specificity for neoplasia was $94.9 \%$ but there was insufficient follow-up to determine sensitivity 25 . The Kaiser-Oakland study found a sensitivity of $68.8 \%$ for cancer $(95 \% \mathrm{CI}$ of $51.1-86.4 \%$ and CI $57.0-76.3 \%$, respectively) and $66.7 \%$ for polyps $>1 \mathrm{~cm}$. Specificity for cancer was reported at $94.4 \%$ and polyps greater than $1 \mathrm{~cm}$ was $95.2 \% \quad(95 \%$ CI 93.8-94.9\% and $94.7-95.7 \%$, respectively). The positive predictive value was $5 \%$ and polyps greater than $1 \mathrm{~cm}$ was $15.5 \%$ (95\% CI 3.2-7.6\% and $12.3-19.3 \%$, respectively) ${ }^{26}$. FOBT has been shown in three separate randomized control trials to decrease colorectal cancer mortality at various rates ranging from $15-33 \% 14-16$. While available to all patient populations and one of the most cost effective, the FOBT has lower sensitivities and specificity (37.1\% to $79.4 \%$ ) compared to other screening modalities, which have improved with newer versions such as Hemaoccult SENSA, but at the expense of specificity $(86.7 \% \text { vs. } 97.7 \%)^{26,27}$. Hemoccult SENSA is more sensitive than Hemoccult II because of a hydrogen peroxide enhancer, which allows for the detection of lower levels of peroixdase activity. The test also requires strict dietary restrictions as the peroxidase activity in red meat and many vegetables and fruits will cause a false positive. The rehydrated 
version of Hemoccult II was abandoned in the 1980s by most investigators because a standard rehydration technique had not been established ${ }^{17}$. Levin et al studied average risk patients with rehydrated Hemoccult II and found a positive test rate of only $14.7 \%$ and positive predictive value for cancer of only $2.6 \% 28$.

FS has been available since 1976. There are several randomized controlled trials associated with decreased CRC mortality when using FS. The first is the NORCCAP study, which randomized 41,913 control group and 13,823 to a screening group $(6,915$ one time FS and 6,908 to FS and FOBT). Although there was no difference in the cumulative hazard of CRC between the screened and control groups after 7-year follow-up, there was reduced mortality of $59 \%$ (hazard ratio $0.41,0.21$ to $0.82, \mathrm{P}=0.011$ ) for colorectal cancer and by $76 \%(0.24,0.08$ to $0.76, \mathrm{P}=0.016)$ for rectosigmoid cancer or those in the attender group in per protocol analysis. All cause mortality was similar in both the screening and control group. However this was subjective to a selection bias because the analysis only included patients from the attender group ${ }^{29}$. The Telemark study was smaller in scale with only 400 patients, but did demonstrate a reduction in the incidence of CRC in Norway with 10 individuals developing CRC in the control group and two in the screening group (relative risk of $0.2 ; 95 \%$ confidence interval $0.03-0.95, p=0.02)^{30}$. The UK Flexible Sigmoidoscopy Screening Trial study is the most recent study involving 170,000 patients, who were randomly assigned to one-time sigmoidoscopy versus usual care, (112, 939 in the control group and 57,099 in the screening group). After 11.2 years follow-up, incidence of colorectal cancer in people attending screening was reduced by $33 \%(0.67,0.60-0.76)$ and mortality by $43 \%{ }^{31}$. Despite these findings, FS as a screening modality is decreasing in use as it does not visualize the entire colon and has a sensitivity of only $60 \%$ to $70 \%$ when compared with colonoscopy ${ }^{30-33}$

Colonoscopy is currently considered the "gold standard" for colorectal screening because it allows for the examination of the entire colon as well as the removal of adenomas that have the potential to transform into cancer. Interestingly, there are currently no prospective randomized control trials that demonstrate a reduction in CRC mortality. A review of the current literature shows that there are both case-control and cohort studies that show a decrease in CRC mortality. One case-control study in a U.S. VA-population demonstrated a $50 \%$ reduction in CRC mortality in symptomatic patients ${ }^{34}$. The National Polyp Study, a cohort study including 1,418 patients, similarly demonstrated a $76 \%$ to $90 \%$ reduction in the incidence of CRC after clearing colonoscopy (in which one or more adenomas of the colon or rectum were removed) compared to three concurrent reference populations ${ }^{35}$.

CT colonography (CTC) or "virtual colonoscopy" was first described in 1994 and involves thin-slice abdominal CT images of an air-filled distended colon that are reconstructed with advanced computer software to create a step-wise display to visualize colonic lesions ${ }^{36,37}$. The development of high-speed 64-row detector CTs, multi-planar 3D displays, and improved bowel preparation procedures have led to improved sensitivity for colonic polyp visualization $37,48-50$. These advances have changed the guidelines such that the ACS-MSTF and ACG now recommend CTC every 5 years as an acceptable alternative screening method to colonoscopy ${ }^{38,39}$. Drawbacks include the continued need for a cathartic bowel preparation prior to the study, a low (but real) risk of perforation from instillation of air ${ }^{40-46}$, as well as the inability to remove polyps if they are found. This would then incur the risk and cost of another procedure, typically colonoscopy, for polypectomy. There are additional concerns related to management and cost of incidental findings on $\mathrm{CT}^{47}$ and the current unknown long-term consequences of radiation exposure.

Another newer screening modality that is available is fecal or stool DNA (sDNA). This modality serves as a non-invasive alternative to colonoscopy when screening for precancerous adenomas by identifying genetic alterations in the initiation of a sequenced progression from adenoma to carcinoma, such as mutations in APC, K-ras, DCC, and p5351-53. Although other noninvasive studies such as FOBT and FIT have been shown to be sensitive for the detection of CRC, sDNA potentially offers improved sensitivity, specificity, and cancer prevention by the detection of adenomas. The reported sensitivity of sDNA testing (Version 1.0) for the detection of CRC ranges from $52 \%$ to $91 \%$, with specificity ranging from $93 \%$ to $97 \%$. The sensitivity of sDNA has also been compared to Hemoccult II sensitivity in a large, prospective trial with 2,507 patients. In this study, sDNA testing detected 16 of 31 invasive cancers versus 4 of 31 detected by FOBT ( $51.6 \%$ vs. $12.9 \%, \mathrm{P}=0.003)$. In a subset analysis of 71 patients with invasive cancer or high-grade dysplastic adenomas, sDNA was significantly more sensitive than FOBT $(40.8 \%$ vs. $14.1 \%, \mathrm{P}$ $<0.001$ ), however both tests had lower sensitivities overall for the detection of isolated advanced neoplasia $(18 \%$ for sDNA vs. $10 \%$ for $\mathrm{FOBT}, \mathrm{P}=0.001)$. Specificity of both tests was similar $(94 \%$ vs. 95\%) $)^{14-15,2618-22,54-55}$. 


\section{Current Colorectal Screening Guidelines and Future Directions}

Several different national and international organizations ranging from the National Cancer Coalition Network (NCCN) to professional societies such as the American College of Gastroenterology (ACG) and American Society of Colon \& Rectal Surgeons (ASCRS) provide clinical practice guidelines (CPGs) for the care and prevention of colorectal cancer. The American Cancer Society, the U.S. Multi-Society Task Force on Colorectal Cancer (ACS-MSTF), and the American College of Radiology jointly provide widely quoted screening guidelines for CRC. The ACS-MSTF employ a strategy of a "menu of options" of screening modalities to allow physicians and their patients to have a tailored approach to encourage screening 38 . This group favors modalities that are colon cancer prevention tests, meaning that they are geared more for identification of adenomatous polyps. Average-risk individuals should begin cancer screening at the age of 50 and African Americans should begin at the age of 45--given their younger mean age of presentation and proximal tumor location. Patients may select from the following tests for colon cancer prevention: flexible sigmoidoscopy every 5 years, colonoscopy every 10 years or double contrast barium enema (DCBE) every 5 years - all along with an annual physical examination. For individuals seeking a less invasive modality for screening there are two tests that are aimed more at detecting cancer: annual FOBT and annual fecal immunochemical testing (FIT). A new alternative accepted method of screening is fecal or stool DNA (sDNA) with no time-line established.

Alternatively, the ACG has a "preferred" strategy for CRC screening with cancer prevention methods being offered first. As such, the preferred method is colonoscopy starting at 50 years of age ( 45 years for African Americans) every 10 years. Alternate methods include: flexible sigmoidoscopy every 5-10 years or CT colonography every 5 years. While not favored, alternate cancer detection tests include annual FIT, annual Hemoccult Sensa or fecal DNA with physical examination every 3 years ${ }^{39}$.

Recently, the American College of Physicians (ACP) published updated guidelines for screening in which they recommended that high-risk asymptomatic individuals should start their screening at the age of 40. Included in this high-risk group are African Americans ${ }^{56}$. Other higher-risk individuals include those with first-degree relatives with diagnosis of colorectal cancer and family history of colorectal cancer before the age of forty. This is a break from the
USPSTF guidelines, which recommends screening for African Americans to start at age forty-five ${ }^{57}$. Whether or not other groups endorse this recommendation has yet to be seen, and will likely warrant more investigation.

The American College of Gastroenterology (ACG) has included two other sub-groups that warrant "special efforts" to include in colorectal cancer screening: smokers and obese patients. Smoking has been demonstrated to cause increased microsatellite instability ${ }^{58}$, which is involved in malignant transformation. Smoking is associated with $\sim 20 \%$ of colorectal cancer in the United States and studies have shown that patients with more than a 20 pack-year history have a 2-3 fold lifetime increase risk in developing $\mathrm{CRC}^{19}$. These patients tend to be diagnosed at a younger age and have more advanced disease, as well as more isolated proximal disease ${ }^{60-61}$. This suggests that colonoscopy should be the screening modality of choice in this group. Obesity is another risk factor that has been long associated with colorectal cancer. While the exact mechanism is unknown, obesity may lead to CRC development by several mechanisms. The first is through the secretion of adipokines, which consists of hormones, cytokines and other signaling molecules. Adipokines are responsible for energy balance, inflammation, insulin sensitivity and angiogenesis $62-63,65$. Hyperinsulinemia and IGF-1 are thought to play a role in the development of cancer by inhibiting apoptosis ${ }^{63}$. Leptin, a glycoprotein expressed by adipocytes, has also been shown to have a key role in inflammation and carcinogenesis. ${ }^{65} \mathrm{Sev}-$ eral studies have reported that both overweight and obese statuses are associated with an increased risk of colorectal cancer ${ }^{58}$. There has also been reports of increased presence and size of adenomas $>1 \mathrm{~cm}$ as well as more high-risk adenomas (i.e., tubuovillous) ${ }^{66-68,14}$.

\section{Is Colorectal Cancer Screening Cost-effective?}

The cost effectiveness of colorectal screening has been studied extensively since the first trial regarding colorectal cancer screening effectiveness was published and the USPSTF first released recommendations urging primary care physicians to screen for colorectal cancer. Lansdorp-Vogelaar et al. recently reviewed 56 studies that analyzed 32 unique colorectal cancer models and their screening strategies. This review sought to answer three questions: a) how do costs and life-years gained (LYG) from colorectal cancer screening with the established screening modalities compare to no screening; b) do the results of the cost-effectiveness analysis of the established screening options point to an optimal strategy of 
screening and; c) are the newly developed screening tests (i.e., FIT, sDNA, CTC and capsule endoscopy) cost-effective compared with the established CRC screening modalities. The review found that screening for colorectal cancer using the established modalities compared to no screening was still a cost-effective measure, or in some cases cost-saving, and that cost-effectiveness has improved over time. Unfortunately, an optimal cost-effective screening strategy was not apparent, although colonoscopy was favored in half of the studies reviewed. Test costs including endoscopy played important drivers as to which strategy was eventually chosen. Newer available screening modalities such as FIT, sDNA, and CTC were also analyzed for their cost-effectiveness compared to the established screening modalities. FIT was cost-effective compared no screening as well as established screening modalities. CTC is considered cost-effective compared to no screening, but is dominated by the other established screening modalities. Stool DNA has not been compared to no-screening strategies, but when compared to established screening options it was not cost-effective because of availability, cost of analysis and the need for further invasive testing if a test is positive. Although these tests are not cost-effective compared to other available screening modalities, the authors concluded that they are still viable options as they may capture a portion of the screening population that is unable or unwilling to utilize the established modalities and thus increase the adherence rate ${ }^{69}$.

\section{Disparities in Colorectal Cancer Screen- ing}

Unfortunately, despite multiple advances in many aspects of $\mathrm{CRC}$, there are still widespread disparities that exist and result in lower CRC screening. Not surprisingly, lack of insurance coverage remains one of the forefront barriers to utilization of CRC screening. Yet, several studies have shown that when insurance coverage is provided for colorectal screening, there are still disparities in age, gender, race and location. This has been demonstrated both in the Medicare population and within the MHS 70-73. Reasons to this both perceived and actual notion are widespread, and at times, confounding.

Ko and colleagues reviewed Medicare beneficiaries in the state of Washington in 1994, 1995 and 1998 after the initiation of universal coverage for FOBT and $80 \%$ of coverage for invasive testing such as colonoscopy and flex sig in high risk individuals. They noted that overall there was under-utilization of CRC screening with less than $6 \%$ of individuals getting any type of colorectal cancer screening test and
$<4 \%$ receiving any screening tests. However, the use of colonoscopy increased from 1994 to 1998, and men, older patients, rural dwellers and African Americans were more likely to get a colonoscopy ${ }^{71}$.

In 2001 when coverage was extended for colonoscopy and other invasive testing in average-risk individuals, the rate of utilization increased slightly. They found that $9.2 \%$ of the screened population had FOBT and were male, in the age group of 70-74 years of age, and resided in a rural setting. Similar to other studies, Hispanics were less likely to get FOBT. While $7.2 \%$ of the screened beneficiaries had an invasive test, only $3.5 \%$ received the test for CRC screening indications. A test was considered screening if the procedure was coded using the relevant HCPCS or ICD9 codes for screening tests and there were no ICD9 diagnosis codes of gastrointestinal tract symptoms, weight loss, anemia associated with physician visits within the previous 3 months for altered bowel habits, abdominal pain, gastrointestinal bleeding, positive fecal occult blood test, weight loss, iron deficiency anemia, anemia, unspecified. Male beneficiaries aged 70-74 years who were white and urban residents were more likely to get an invasive test. Of the invasive tests, colonoscopy was utilized $58 \%$ of the time. Again male, ages 70-74 years, whites and urban residents were more likely to have a colonoscopy as their screening modality. Hispanics were less likely to utilize invasive testing. The results of the study demonstrated that full coverage did not improve disparities in utilization, but colonoscopy was being utilized more once it was covered $100 \%{ }^{70-72}$. Whether this was secondary to either reimbursement or coverage issues was not mentioned, though continues to be a topic of debate today.

Brounts and associates demonstrated that within the MHS at a major military medical center, the compliance rate with CRC screening was $71 \%$. In the study, the demographics consisted of $50 \%$ were male and $42 \%$ were older than 65 years of age. The ethnic breakdown was $69 \%$ white, $14 \%$ African Americans, $12 \%$ Hispanic and 5\% other. Further analysis revealed that men, Caucasians and patients older than 65 years were utilizing CRC screening in greater amounts, despite the fact that all demographics had similar access to the testing. Colonoscopy was used $40 \%$ of the time for CRC screening and was the most common screening modality chosen ${ }^{73}$.

These findings suggest that although there is gradual increase in the rate of utilization of CRC screening overall, there is still a disparity between gender, age, race and residence. Males who are older than 65 to 70 years of age residing in an urban location are more likely to be screened and use colonoscopy as 
a modality for this screening. Somewhat surprising, within the MHS the findings are similar, suggesting that access may not the primary reason for lack of screening, but may extend to other issues such as patient education, personal beliefs or reasons that have not been determined.

\section{Colorectal Screening Among Different Minority Groups}

African Americans have the highest incidence of CRC of any racial or ethnic group and survival from CRC in African Americans is consistently lower than in Whites in the literature. From 1996 to 2000, incidence rates in African Americans were 12.3\% higher than those of Whites--9.5\% higher in African American males compared to white males and $17.5 \%$ higher in female African Americans compared to white females $^{74}$. The reasons for higher incidence rates in African Americans are unclear. Physical inactivity, dietary and nutritional factors, variability in screening rates, lower use of diagnostic testing and increased smoking have all been implicated ${ }^{75}$. Mean age of presentation of CRC in African Americans in lower when compared to whites and a higher proportion of African Americans present at $<50 \mathrm{yrs}$ of age. Theuer et al. found that $10.6 \%$ of African Americans vs. $5.5 \%$ of Whites presented before the age of fifty. African Americans also have been found to decrease survival with a greater proportion presenting with advanced disease $^{76}$. Factors cited have been lower screening rates, less use of diagnostic tests and less access to health care. For the above stated reasons, the recommended screening age for average risk individuals who are African Americans is forty-five. Treatment of advanced disease also varies between African Americans and Whites in the public sector, which again demonstrates decreased survival in African Americans. This is not the case in equal access populations such as the VA health system or MHS in which there is either no or minimal differences in survival when compared to Whites ${ }^{77}$. Some of the barriers to screening specifically within the African American population include: limited knowledge of how CRC may personally effect an individual, adverse attitudes toward physical examination techniques to detect CRC such as the DRE as well as the belief or skepticism regarding the underlying intent of White physicians for patients of different ethnic backgrounds (Tuskegee Effect) ${ }^{78}$.

Hispanics are the largest and fastest growing ethnic group in the U.S ${ }^{79}$. However, there have been documented disparities in cancer screening utilization and compliance. As a result, Hispanic men are more likely to be diagnosed with more advanced malig- nancy, and have poorer cancer-specific survival compared to White non-Hispanic men ${ }^{80-82}$. This has significant public health implications. In 1999, the CDC initiated a Screen for Life multi-year campaign to educate adults older than 50 years about the importance of regular colorectal cancer screening and increase cancer-screening rates in all ethnic groups $^{84-86}$. Annual health surveys were conducted and Zhou et al analyzed the results of the 2000 and 2005 cancer control modules to asses whether colorectal, prostate and skin cancer screening rates had varied overtime for the Hispanic population. They found that Hispanics were less likely to comply with current cancer screening recommendations when compared to White non-Hispanic men, although there was an overall increase in colorectal screening and use of endoscopy in all ethnic groups ${ }^{87}$. This was consistent with previous studies using NHIS data. The disparity seen in Hispanics is likely multi-factorial to include as lower socioeconomic status, lower education, lower acculturation, cultural and language barriers in seeking and obtaining cancer information, and less access to healthcare services ${ }^{87-93,74}$. It may also be difficult to accurately assess this patient population for cancer screening, as they are more likely to respond to screening questions or surveys in a socially desirable manner and may actually over-report ${ }^{94,95}$.

Within the Asian American population, there are also decreased screening rates when compared to Whites, however the precise reasons for sub-optimal screening among this group are not known and very few population studies have been completed regarding cancer screening in the last decade. Homayoon et al looked at Asian American communities in California and found that there was a screening rate of $58 \%$ compared to $66 \%$ of whites, with the Filipino and Japanese sub-groups having cancer screening rates similar to Whites. As an overall group, demographic factors such as insurance status, English proficiency and site of birth did not contribute the disparity. The reasons for decreased screening appeared to be varied according certain sub-groups with Korean and Chinese Americans demonstrating a lack of understanding regarding the importance of CRC and its impact on the individual but in Vietnamese populations, access to care and lack of insurance was the found to be related to decreased diagnostic screening rates. It appears that the main driver in the Asian population group overall is related to a lack of awareness regarding the importance of preventive health measures ${ }^{96}$.

While there are significant variations in CRC screening based on ethnicity categories, this should not be surprising. Such a wide array of factors play a 
role in the attitudes and actions of individual patients - these are magnified when any large group of people are "clumped" together - especially in regards to race. Yet this doesn't take away from the fact that CRC screening rates, and ultimately outcomes, are worse in Hispanics and African Americans. Although targeted education and screening programs have seen some benefit towards ameliorating this disparity, much more remains to be done to lessen this gap.

\section{The Military Health System}

The Military Health System or MHS provides healthcare to active duty and retired US military personnel and their dependents ${ }^{97-99}$. Its primary mission is to provide health support for the full range of military operations and sustain the health of all 9.6 million beneficiaries assigned to it. TRICARE is a component of the MHS that provides civilian healthcare for all beneficiaries not involved in contingency or combat operations. The MHS comprises of 65 hospitals and 412 outpatient clinics, in addition to contingency and combat-theater operations worldwide--all with an operating budget of $\$ 46$ billion $^{100,101}$. This is in contrast with the Veterans Administration health system or VHS, which cares for primarily military veterans, and rarely some dependents, based off of a system of eight priority groups. Grouping is determined by a percentage of service-connected disabilities or illness at time of separation ${ }^{102}$. Those in the first three priority groups have greater access to care then the remaining five. It has 152 medical centers and 1,400 outpatient clinics servicing 8.3 million veterans per year ${ }^{103}$. The patient population tends to overall male and older; however, this is changing as a result of the recent wars in Afghanistan and Iraq where women have played an ever-increasing role.

Currently, the MHS has a multi-modality, population-based strategy for CRC screening. Brounts et al reviewed institutional data from a major military medical center that demonstrated an increasing use of colonoscopy compared to FS and DBCE. As stated, colonoscopy was used $40 \%$ of the time for CRC screening and was the most common screening modality chosen ${ }^{73}$. Patients were screened in various settings, both episodic formats such as the doctor's office in multiple specialties, as well as through outreach programs such as annual health fairs and mailed reminders. The use of the military's electronic medical record, AHLTA, assists with electronic reminders for providers in patient encounters. In addition, there is use of the Military Health System Population Health Portal, a secure web-based tool that is utilized by the Army Medical Department (AMEDD) that assists in population health and system improvement. It can identify Tricare beneficiaries that are behind in suggested preventive clinical management services ranging from diabetic care, mammography and colorectal cancer screening ${ }^{73}$. As the result of both in-house and outreach tools, more patients within the MHS are being screened at a rate of $71 \%$ compared to $65 \%$ screening rate within the civilian population. As previous studies have shown, access to care is not the only barrier to being screened for CRC, but instead gender, age, race and socioeconomic status can also be limiting factors. The MHS has likely improved its screening rate by utilizing technology, multiple screening modalities that are part of a population screening strategy and community outreach via mailed reminders and health fairs that offer opportunities to both screen and educate patients. The next steps in the MHS to increase CRC screening are targeted education and screening campaigns to minority groups, such as African Americans and Hispanics, which have lower overall screening rates despite having equal access to care, as well as, patients younger than 65 . Colonoscopy remains the favored modality both for screening and therapeutic reasons, but should not be the only one utilized as the MHS attempts to capture a greater patient population.

\section{Colorectal Screening Strategies in Social- ized Healthcare: Population-Based Strat- egies}

The VA Health system (VHS) currently favors the use of FOBT over colonoscopy ${ }^{102}$. Although the reason for this is unclear, it may be related to availability of FOBT compared to colonoscopy, local VA policies or patients may be utilizing colonoscopy as a screening method as a Medicare patient. The VHS uses their EMR, Vista, to screen patients for cancer screening and other preventive measures, and approach the patient during office visits. Recently, the San Diego VA and New Mexico VA system has made attempts at decentralization of CRC screening by adopting outreach programs ${ }^{105,106}$. In San Diego a blinded RCT was conducted in which patients were sent mailed reminders after picking up their FOBT cards to increase compliance. The primary outcome was the number of returned cards after 6 months. In the intervention group, FOBT cards were returned in $64.6 \%$, with more than $90 \%$ returning the cards in the first 90 days compared to the control group with a $48.4 \%$ return rate. Cost-effectiveness of the intervention was also reviewed. Total cost was $\$ 962$ or $\$ 2.49$ per patient, with an incremental cost of $\$ 15$ per additional patient screened ${ }^{105}$. The New Mexico VA identified CRC screening through doctor visits as a system 
barrier in a 2011 study and conducted a RCT in which patients were mailed FIT and FOBT cards after being contacted via phone or mail in the intervention groups or continued with usual care in the control group. The study found that control patients were less likely to undergo FOBT, more likely to receive care in a community based outpatient clinic (CBOC) and less likely to be non-Hispanic white. Screening occurred less often in the control groups averaging $17 \%$ in the control groups compared to $48.5 \%$ in the intervention group ${ }^{106}$. The estimated cost was $\$ 240^{107}$.

The VHS utilizes a population-based strategy and has begun to focus on decentralized outreach programs in order to improve their screening rate. There is a tiered approach with the FOBT forming the basis of CRC screening, but the availability of other modalities continues to allow for multiple opportunities to screen. Again there is the issue of decreased screening rates in minorities that is present throughout the United States and remains a real challenge for all systems. There may also be a de-facto access to care barrier as VA patients receive care based on their priority grouping. Patients that are in the fifth through eighth priority group may only receive care for certain service-related conditions and therefore may not have access to all screening modalities so cost-effective screening strategies such as FOBT may allow for more veterans to be screened

The National Health System is the publicly funded health system of the United Kingdom and is funded through general taxation rather than insurance payments. All legal residents of the United Kingdom are eligible for comprehensive healthcare to include doctor visits, nursing services, hospital inpatient stay and services, mental health services, surgical procedures or appliances, consumables such as medications, supplies, imaging such as X-rays, CT or MRI scans ${ }^{108}$. In 2006, the NHS initiated the National Bowel Cancer Screening Program (NBCSP), which utilized biennial FOBT testing on patients aged 60-69 years of age with follow on endoscopy for abnormal tests. As of 2011, one million FOBT have been performed with uptake at $50-60 \%$ in the provinces and $40 \%$ in London. Cancer was found in $11.6 \%$ and $7.8 \%$ men and women, respectively, and high-risk adenomas were detected in $43 \%$ and $29 \%$ of men and women, respectively ${ }^{109}$. The UK Flexible Sigmoidoscopy trial recently reported its results with a reduction in 36\% distal CRC and 2\% distal CRC and a $31 \%$ reduction in mortality in the intention to treat analysis. Number needed to screen to prevent cancer was $191^{31}$. The results of this trial were confirmed by the Italian SCORE trial in which 9,911 subjects were screened using a once flexible sigmoidoscopy in a similar age group. Incidence of CRC in the intervention group was decreased by $18 \%$ and mortality was non-significantly reduced by $22 \%$ compared to the control group 110,111 . Cost-effectiveness of the UK trial has been analyzed by Lansdorp et al and more recently by Whyte et al who utilized a state transition model and CRC natural history model simultaneously, and found that single FS showed the greatest QALY at the age of 55 years with a combined strategy of FS and FOBT showing improved benefits and economic outcomes ${ }^{69,112}$.

The NHS utilizes biennial FOBT as the basis of their screening program, but with the recent UK Flexible trial and SCORE trial results, it remains to be seen whether single FS will be adopted by the NBSCP as an additional at this time, but the trial results are encouraging.

Moiel et al. recently reviewed Kaiser-Permante Northwest (KPNW) colorectal screening strategy over the past 30 years starting in 1980 and made 6 different changes in preferred screening modalities based off of best practices. KPNW provides medical care to 500,000 beneficiaries from the southwest Washington, Portland and Salem, Oregon areas. They began their colorectal screening program in 1980 with office-based FOBT with a screening detection rate of 5\% and then switched to home-based FOBT in 1985. In 1995 national guidelines began to favor endoscopic based testing and flexible sigmoidoscopy became the screening modality of choice. In the 2006, colonoscopy replaced flexible sigmoidoscopy, but the screening detection rate fell to 5\%, despite increasing in-reach and outreach programs, number of endoscopists and increasing the number of CRC early stage detection. This resulted in a switch from individual screening strategy to a population-based screening strategy in which KPNW returned to FOBT use. Subsequently, they then switched to FIT in the 2010, and coupled this with an aggressive in-reach and outreach program directed at both patients and healthcare providers. By 2010, the screening detection rate had increased to $33 \%$. The number of colonoscopies performed increased as well, but reflected the number of scopes performed because of positive FOBT and FIT. KPNW also examined current metrics such as the number of tests performed, stage of disease and percentage of screen-detected cases using their Tumor registry to assess the success of their screening strategy. They noted that the number of tests and stage of disease did not accurately reflect the success of screening efforts ${ }^{113}$. The new screening strategy and improvement in successful detection rate demonstrates the importance of continuously reviewing screening options for screening populations, and 
emphasizes the need for both in-reach and out-reach programs to increase the CRC screening rate.

\section{Conclusion}

The goal of any method early cancer detection is to discover cancer at its earliest stage, or ideally in the pre-malignant phase. A good cancer-screening test is one that is not only accurate and specific, but also widely accepted by the screening population. While colonoscopy has been the "preferred screening method", it is not the only effective method in terms of reducing incidence and mortality from colorectal cancer, as other modalities such as FOBT and flexible sigmoidoscopy have demonstrated in large randomized control trials. Colonoscopy, while accurate and effective in preventing colorectal cancer by polypectomy, misses a portion of the screening population either due to availability or patient non-preference. Whether this is related to cultural belief, cost reasons, access to care, or other factors is open to debate, and likely multi-factorial. The cost-effectiveness of colorectal screening compared to no screening has been proven in multiple analyses with some modalities showing greater benefit over others. Many socialized healthcare systems as well as a large managed care organization have adopted a population-based strategies in an effort to capture more of their screening populations. The MHS currently supports a population-based strategy with a robust in-reach and outreach programs through electronic medical records with electronic reminder system, the MHS Population Health Portal, patient and provider education campaigns, as well as health fairs with multiple screening modalities available to patients. In order to reduce to the incidence and mortality of colorectal cancer it is more important to screen as many patients as possible with a screening modality that is safe, effective and amenable to the patient both with cost and comfort rather than attempting to screen with the best test.

\section{Disclaimers}

The views expressed are those of the author(s) and do not reflect the official policy of the Department of the Army, the Department of Defense or the U.S. Government.

\section{Competing Interests}

The authors have declared that no competing interest exists.

\section{References}

1. [Internet] US Cancer Statistics Working Group. United States Cancer Statistics (USCS): 1999-2007 incidence and mortality data. http://www.cdc.gov/uscs.
2. Parkin DM, Bray F, Ferlay J, et al. Global cancer statistics, 2002. CA Cancer J Clin. 2005; 55(2): 74-108.

3 [Internet] http://seer.cancer.gov/csr/1975_2009_pops09/ results_single/sect_01_table.01.pdf.

4. Mariotto AB, Yabroff KR, Shao Y, Feuer EJ, Brown ML. Projections of the cost of cancer care in the United States: 2010-2020. J Natl Cancer Inst 2011; 103:117-28.

5. Ekwueme DU, Guy GP, Li C, Rim SH, Parelkar P, Chen SC. The health burden and economic costs of cutaneous melanoma mortality by race/ethnicity-United States, 2000-2006. J Am Acad Derm 2011 Nov; 65(5 Suppl 1): S133-43

6. Lansdorp-Vogelaar I, van Ballegooijen M, Zauber AG, Habbema JD, Kuipers EJ. Effect of rising chemotherapy costs on the cost savings of colorectal cancer screening. J Natl Cancer Inst 2009; 101:1412-22.

7 Richardson LC, Tai E, Sun HR, Djenaba J and Plescia M. Vital Signs: Colorectal Cancer Screening, Incidence, and Mortality -- United States, 2002-2010. Weekly 2011; 60(26):884-889.

8. [Internet] US Preventive Services Task Force. Screening for colorectal cancer. Rockville, MD: Agency for Healthcare Research and Quality; 2008. http://www.uspreventiveservicestaskforce.org/uspstf/ uspscolo.htm.

9. Hofstad B, Vatn M. Growth rate of colon polyps and cancer. Gastointest Endosc Clin N Am 1997; 7:345-363.

10. Winawer SJ, Fletcher RH, Miller L, et al. Colorectal cancer screening: clinical guidelines and rationale. Gastroenterology 1997; 112:594.

11. Force Screening for colorectal cancer: U.S. Preventive Services Task Force recommendation statement. Ann Intern Med 2008; 149:627.

12. Wong JL, Hawkins NJ, Ward RL. Colorectal Cancer: A Model for Epigenetic Tumorigenesis. Gut 2007; 56:140-148.

13. [Internet] US Department of Health and Human Services. Healthy people 2020. http://www.healthypeople.gov/2020/topicsobjectives2020/ default.aspx.

14. Hardcastle JD, Chanberlain JO, Robinson MH et al. Randomized controlled trial of faecal-occult-blood screening for colorectal cancer. Lancet 1996; 348:1472-1477.

15. Kronborg O, Fenger C, Olsen J, et al. Randomized study of screening for colorectal cancer with faecal-occult-blood test. Lancet 1996; 348:1467-1471.

16. Wilson JM and Junger G. Principles and Practice of Screening for Disease. Geneva, Switzerland: World Health Organization; 1968.

17. Allison JE. Fecal Occult Blood Testing for Colorectal Cancer. Alim Pharm Ther 1998; 12(1): 1-10

18. Gopalswanny N, Stelling HP, Markert RJ, et al. A comparative study of eight fecal occult blood tests and HemoQuant in patients in whom colonoscopy is indicated. Arch Fam Med 1994; 3: 1043-1048.

19. Greenberg PD, Bertario L, Gnauk R, et al. A prospective multicenter evaluation of new fecal occult blood tests in patients undergoing colonoscopy. Am J Gastroenterol 2000; 95:1331-1338.

20. Levi Z, Rozen P, Hazazi R, et al. A quantitative immunochemical fecal occult blood test for colorectal neoplasia. Ann Intern Med 2007; 146:244-255.

21. Smith A, Young GP, Cole SR, et al. Comparison of a brush-sampling fecal immunochemical test for hemoglobin with a sensitive guaiac-based fecal occult blood test in detection of colorectal neoplasia. Cancer 2006; 107:2152-2159.

22. Wong BC, Wong WM, Cheung KL, et al. A sensitive guaiac faecal occult blood test is less useful than an immunochemical test for colorectal cancer screening in a Chinese population. Aliment Pharmacol Ther 2003; 18:941-946.

23. Petrelli N, Michalek AM, Freedman A, Baroni M, Mink I, Rodriguez-Bigas M. Immunochemical versus guaiac occult blood stool tests: results of a community-based screening program. Surg Oncol 1994; 3: 27 36.

24. St. John DJB, Young GP, Alexeyeff MA, et al. Evaluation of new occult blood tests for detection of colorectal neoplasia. Gastroenterology 1993; 104: 1661-8.

25. Robinson MHE, Marks CG, Farrands PA, Thomas WM, Hardcastle JD. Population screening for colorectal cancer: comparison between guaiac and immunological faecal occult blood tests. Br J Surg 1994; 81: 448-51.

26. Allison JE, Tekawa IS, Ransom LJ, Adrain AL. A comparison of fecal occult-blood tests for colorectal-cancer screening. N Engl J Med 1996; 334: 155-9.

27. Miller S and Steele SR. Novel Molecular Screening Approaches in Colorectal Cancer. J Surg Oncol 2012; 105 (5): 459-67

28. Levin B, Hess K, Johnson C. Screening for colorectal cancer: a comparison of three fecal occult blood tests. Arch Intern Med 1997; 157: 970-6. 
29. Hoff G, Grotmol T, Skovlund E, et al. Risk of colorectal cancer seven years after flexible sigmoidoscopy screening: randomized controlled trial. BMJ 2009;338: b1846

30. Thiis-Evensen E, Hoff GS, Sauar J, et al. Population-based surveillance by colonoscopy: effect on the incidence of colorectal cancer. Telemark Polyp Study I. Scand J Gastroenterol 1999;34 (4): 414-20

31. Atkin WS, Edwards R, Kralj-Hans I, et al. Once-only flexible sigmoidoscopy screening in prevention of colorectal cancer: a multicentre randomized controlled trial. Lancet 2010;375 (9726): 1624-33

32. Imperiale $\mathrm{TF}$, Wagner $\mathrm{DR}$, Lin $\mathrm{CY}$, et al. Risk of advanced proximal neoplasms in asymptomatic adults according to the distal colorectal findings. N Engl J Med 2000; 343:169-174.

33. Lieberman DA, Weiss DG, Bond JH, et al. Use of colonoscopy to screen asymptomatic adults for colorectal cancer. Veterans Affairs Cooperative Study Group 380. N Engl J Med 2000; 343:162-168.

34. Muller AD, Sonnenberg A. Prevention of colorectal cancer by flexible endoscopy and polypectomy. A case-control study of 32,702 veterans. Ann Intern Med 1995; 123:904-910.

35. Winawer SJ, Zauber AG, Ho MN, et al. Prevention of colorectal cancer by colonoscopic polypectomy. The National Polyp Study Workgroup. N Engl J Med 1993; 329: 1977-1981

36. Vining, DJ. Virtual endoscopy: Is it a reality? Radiology 1996; 200:30.

37. Zauber AG, Levin TR, Jaffe CC, Galen BA, Ransohoff DF and Brown ML. Implications of New Colorectal Cancer Screening Technologies for Primary Care Practice. Medical Care 2008; 46: 138-146.

38. Levin B, Lieberman DA, McFarland B, et al. Screening and surveillance for the early detection of colorectal cancer and adenomatous polyps, 2008: a joint guideline from the American Cancer Society, the US Multi-Society Task Force on Colorectal Cancer, and the American College of Radiology. CA Cancer J Clin 2008; 58:130.

39. Rex DK, Johnson DA, Anderson JC, et al. American College of Gastroenterology guidelines for colorectal cancer screening 2008. Am J Gastroenterol 2009; 104:739-750.

40. Coady-Fariborzian L, Angel LF, Procaccino JA, et al. Perforated colon secondary to virtual colonoscopy: report of a case. Dis Colon Rectum 2004; 47(7): 1247-9.

41. Kamar M, Portno O, Bar-Dayan A, et al. Actual colonic perforation in virtual colonoscopy: report of a case. Dis Colon Rectum 2004; 47:1242-1246.

42. Atalla MA, Rozen WM, Master M, McLaughlin S. Colonic perforation during 'virtual' CT colonography. J Gastrohepatol 2009; 24 (11): 1800

43. Bassett JT, Liotta RA, Barlow D, Lee D, et al. Colonic perforation during screening CT colonography using automated $\mathrm{CO} 2$ insufflation in an asymptomatic adult. Adom Imaging. 2008; 33(5): 598-600.

44. Belo-Oliveira P, Curvo-Semedo L, Rodrigues H, Belo-Soares $\mathrm{P}$, et al. Sigmoid Colon Perforation at CT Colonography Secondary to a Possible Obstructive Mechanism: Report of a Case. Dis Col Rectum. 2007; 50(9): 1478-1480.

45. Khan JS, Moran BJ. Iatrogenic Perforation at Colonic Imaging. Colorectal Dis 2011 May; 13(5): 481-93

46. Sosna J, Blachar A, Amitai M, Barmeir A, et al. Colonic Perforation at CT Colonography: Assessment of Risk in a Multicenter Large Cohort. J Rad. 2006; 239(2): 457-463.

47. Veerappan GR, Cash BD. Should computed tomographic colonography replace optical colonoscopy in screening for colorectal cancer? Polskie Archiwum Medycyny Wewnetrznej 2009; 119: 236-240.

48. Cotton PB, Durkalski VL, Pineau BC, et al. Computed tomographic colonography (virtual colonoscopy): a multicenter comparison with standard colonoscopy for detection of colorectal neoplasia. JAMA 2004; 291:1713-1719.

49. Mulhall, BP, Veerappan GR, Jackson, JL. Meta-analysis: computed tomographic colonography. Ann Intern Med 2005; 142:635-650.

50. Johnson CD, Chen MH, Toledano AY, et al. Accuracy of CT colonography for detection of large adenomas and cancers. N Engl J Med. 2008; 259:1207-1217.

51. Zitt M, Zitt M, Muller HM. DNA methylation in colorectal cancer-Impact on screening and therapy monitoring modalities? Disease Markers 2007;23: 51-71.

52. Fearon ER, Vogelstein B. A genetic model for colorectal tumorigenesis. Cell 1990;61: 759-767.

53. Lengauer C, Kinzler KW, Vogelstein B. Genetic instabilities in human cancers. Nature 1998;396: 643-649.

54. Wilson JM and Junger G. Principles and Practice of Screening for Disease. Geneva, Switzerland: World Health Organization; 1968.

55. Morikawa T, Kato J, Yamiji Y, et al. A comparison of the immunochemical fecal occult blood test and total colonoscopy in the asymptomatic population. Gastroenterology 2005; 129:422-428.
56. Qaseem A, Denberg TD, Hopkins Jr RH, Humphrey LL, Levine J, Sweet DE, and Shekelle P. Screening for Colorectal Cancer: A Guidance Statement from the American College of Physicians. Ann Intern Med 2012; 156: $378-386$

57. [Internet] US Preventive Services Task Force. Screening for colorectal cancer. Rockville, MD: Agency for Healthcare Research and Quality; 2008. www.uspreventiveservicestaskforce.org/uspstf/uspscolo.htm.

58. Slattery ML, Curtin K, Anderson K et al. Associations between cigarette smoking, lifestyle factors, and microsatellite instability in colon tumors. J Natl Cancer Inst 2000; 92: 1831 - 6.

59. Giovannucci E. An updated review of the epidemiological evidence that cigarette smoking increases risk of colorectal cancer. Cancer Epidemiol Biomarkers Prev 2001; 10: 725 - 31.

60. Campbell RJ, Ferrante JM, Gonzalez EC et al. Predictors of advanced stage colorectal cancer diagnosis: results of a population-based study. Cancer Detect Prev 2001; 25: 430- 8 .

61. Anderson JC, Alpern Z, Messina CR et al. Predictors of proximal neoplasia in patients without distal adenomatous pathology. Am J Gastroenterol 2004; 99: 472 -7.

62. Giovannucci E. Nutrition, Insulin, Insulin-Like Growth Factors and Colon Cancer: A Review of the Evidence. Horm Metab Res 2003; 35: 694-704

63. Giovannucci E. Insulin, Insulin-Like Growth Factors and Colon Cancer: A Review of the Evidence. J Nutr 2001; 131: 3109s-3120s

64. Schoen RE, Tangen CM, Kuler LH et al. Increased blood glucose, insulin, body size and incidental colon cancer. J Natl Cancer Inst 1999; 91: 1147-54

65. Siddiqui AA. Metabolic Syndrome and its Association with Cancer: A Review. Am J Med Sci March 2011; 341 (3): 227-231

66. Bird CL, Frankl HD, Lee ER et al. Obesity, weight gain, large weight changes, and adenomatous polyps of the left colon and rectum. Am J Epidemiol 1998; 147: 670 -80.

67. Shinchi K Kono S, Honjo S et al. Obesity and adenomatous polyps of the sigmoid colon. Jpn J Cancer Res 1994; 85: 479 -84.

68. Neugut AI, Lee WC, Garbowski GC et al. Obesitous polyps. J Natl Cancer Inst 1991; 83: 359-61.

69. Lansdorp-Vogelaar I, Knudson AB and Brenner H. Cost-effectiveness of Colorectal Cancer Screening. Epidemiol Rev 2001; 33(1): 88-100.

70. Ko CW, Kreuter W, Baldwin LM. Persistent demographic differences in colorectal cancer screening utilization despite Medicare reimbursement. BMC Gastroenterol. 2005; 5:10.

71. Ko CW, Kreuter W, Baldwin LM. Effect of Medicare coverage on use of invasive colorectal cancer screening tests. Arch Intern Med. 2002; 162(22): 2581-6.

72. Schneider EC, Rosenthal M, Gatsonis CG, Zheng J, Epstein AM. Is the type of Medicare insurance associated with colorectal cancer screening prevalence and selection of screening strategy? Med Care. 2008 Sep; $46(9$ Suppl 1): S84-90.

73. Brounts LR, Lehmann RK, Lesperance KE, Brown TA and Steele SR. Improved Rates of Colorectal Cancer Screening in an equal access population. Am J Surgery 2009 197: 609-613

74. [Internet] Rise LAG, Eisner MP, Kosary CL et al. SEER Cancer statistics review, 1975-2000, Bethesda (MD): National Cancer Institute. http://seer.cancer.gov/csr/1975-2000, 2003

75. Agrawal S Bhupinderjit A, Bhutani MS, Boardman L, Nguyen C, Romero Y, Srinivasan R, Figueroa-Moseley C. Colorectal Cancer in African Americans. Am J Gastroenterol 2005; 100: 515-523

76. Theuer CP, Wagner JL, Taylor TH, Brewster WR, Tran D, McLaren CE and Anton-Culver H. Racial and Ethnic CRC patterns affect the cost-effectiveness of CRC screening in the US. Gastroenterology 2001; 120: $848-56$

77. Hassan MO and Steele SR. Race does not impact CRC treatment or outcomes with equal access. Am J Surgery 2009 197: 485-490

78. Bastaini R, Gallardo NV, Maxwell AE. Barriers to Colorectal Cancer Screening Among African American. J Psycho Oncol 2001; 19: 113-32

79. [Internet] US Census Bureau. US Hispanic Population Surpasses 45 Million Now Fifteen Percent Total. http://www.census.gov/ newsroom/releases/archives/population/cb08-67.html

80. Goel MS, Wee CC, McCarthy EP, Davis RB, Ngo-Metzger Q, Phillips RS: Racial and ethnic disparities in cancer screening: the importance of foreign birth as a barrier to care. J Gen Intern Med. 2003; 18:1028-1035.

81. Swan J, Breen N, Coates RJ, Rimer BK, Lee NC: Progress in cancer screening practices in the United States: results from the 2000 National Health Interview Survey. Cancer. 2003; 97:1528-1540.

82. Reyes-Ortiz CA, Eschbach K, Zhang DD, Goodwin JS: Neighborhood composition and cancer among Hispanics: tumor stage and size at time of diagnosis. Cancer Epidemiol Biomarkers Prev. 2008; 17:2931-2936. 
83. Stefanidis D, Pollock BH, Miranda J, et al. Colorectal cancer in Hispanics: a population at risk for earlier onset, advanced disease, and decreased survival. Am J Clin Oncol. 2006; 29:123-126.

84. Coughlin SS, Costanza ME, Fernandez ME, et al. CDC-funded intervention research aimed at promoting colorectal cancer screening in communities. Cancer. 2006; 107:1196-1204.

85. Miller SE, Hager P, Lopez K, Salinas J, Shepherd WL: The past, present, and future of comprehensive cancer control from the state and tribal perspective. Prev Chronic Dis. 2009; 6:A112.

86. Townsend JS, Richardson LC, Steele CB, White DE: Evidence-based interventions and screening recommendations for colorectal cancer in comprehensive cancer control plans: a content analysis. Prev Chronic Dis. 2009; 6: A127.

87. Zhou J, Enewold L, Peoples GE, McLeod DG, Potter JF, Steele RS, Clive KS, Stojandinovic A and Zhu K. Colorectal, Prostate and Skin Cancer Screening among Hispanic and White Non-Hispanic Men, 2000-2005. J Natl Med Assoc 2011; 103: 343-350.

88. Shah M, Zhu K, Potter J: Hispanic acculturation and utilization of colorectal cancer screening in the United States. Cancer Detect Prev. 2006; 30:306-312.

89. Cameron KA, Francis L, Wolf MS, Baker DW, Makoul G: Investigating Hispanic/Latino perceptions about colorectal cancer screening: a community-based approach to effective message design. Patient Educ Couns. 2007; 68:145-152.

90. Jerant AF, Arellanes RE, Franks P: Factors associated with Hispanic/non-Hispanic white colorectal cancer screening disparities. J Gen Intern Med. 2008; 23:1241-1245.

91. Walsh JM, Kaplan CP, Nguyen B, Gildengorin G, McPhee SJ, Perez-Stable EJ: Barriers to colorectal cancer screening in Latino and Vietnamese Americans. Compared with non-Latino white Americans. J Gen Intern Med. 2004; 19:156-166.

92. Vanderpool RC, Kornfeld J, Rutten LF, Squiers L: Cancer information-seeking experiences: the implications of Hispanic ethnicity and Spanish language. J Cancer Educ. 2009; 24:141-147.

93. Davis SW, Diaz-Mendez M, Garcia MT: Barriers to seeking cancer information among Spanish-speaking cancer survivors. J Cancer Educ. 2009; 24:167-171.

94. Hopwood CJ, Flato CG, Ambwani S, Garland BH, Morey LC: A comparison of Latino and Anglo socially desirable responding. J Clin Psychol. 2009; 65:769-780.

95. Velasquez RJ, Callahan WJ, Young R: Hispanic-white MMPI comparisons: does psychiatric diagnosis make a difference? J Clin Psychol. 1993; 49:528-534

96. Homayoon B et al. Impact of Asian Ethnicity on CRC Screening. Am J Clin Oncol 2012.

97. Best Jr., Richard A. Military Medical Care Services: Questions and Answers (2005-05-05). Congressional Research Service. 2005.

98. United States Department of Defense. Task Force on the Future of Military Health Care: Final Report. 2007.

99. [Internet] Official website of the Tricare Management Activity. What is TRICARE? http://www.tricare.mil/tma/.

100. [Internet] http://www.health.mil/About_MHS/FAQs.aspx

101. [Internet] The Quadruple Aim: Working Together, Achieving Success MHS $2011 \quad$ Stakeholders Report. http://health.mil/About_MHS/StakeholdersReport.aspx

102. El-Serag H, Petersen L, Hampel H, Richardson P and Cooper G. The Use of Screening Colonoscopy for Patients Cared for by the Department of Veterans Affairs. Arch Intern Med 2006; 166: 2202-2208.

103. [Internet] http://www.va.gov/health/aboutVHA.asp.

104. [Internet] http://www.va.gov/healtheligibility.

105. Hoffman RM, Steel SR, Yee EF, Massie L, Schrader RM, Moffett ML, Murata GH. System-based Intervention to Improve CRC Screening Uptake. Am J Manag Care 2011 Jan; 17 (1): 49-55

106. Lee JK, Reis V, Liu S, Conn L, Groessl EJ, Ganiats TG, Ho SB. Improving FOBT Testing Compliance Using Mailed Education Reminder. J Gen Intern Med 2009 Nov; 24 (11): 1192-1197

107. Lee JK, Groessl EJ, Ganiats TG and Ho BS. Cost-effectiveness of Mailed Education Reminder to Increase CRC. BMC Gastroenterol 2011 Aug 25; 11: 93

108. [Internet] The NHS Constitution for England, (2012 Edition). http://www.dh.gov.uk/en/Publicationsandstatistics/Publications/Pu blicationsPolicyAndGuidance/DH_132961

109. Logan RFA, Patnick J, Nickerson C, Coleman C, Rutter MD and von Wagner C. Outcomes of the Bowel Cancer Screening Program (BCSP) in England after the first 1 million tests. Gut 2012 Oct;61(10):1439-46.
110. Segnan N, Armaroli P, Bonelli L, et al. Once-only sigmoidoscopy in colorectal cancer screening: follow-up findings of the Italian randomized controlled trial-SCORE. J Natl Cancer Inst. 2011; 103(17): 1310-1322.

111. Church TR. Screening for Colorectal Cancer-Which Strategy is Best? JNCI Sept 2011; 103 (17): 1282-1283

112. Whyte S, Chilcott J, Halloran S. Reappraisal of Options for Colorectal Cancer Screening in England. Colorectal Dis 2012 ; Epub ahead of print

113. Moiel D and Thompson J. Early Detection of Colon Cancer - The Kaiser Permanente Northwest 30-Year History: How Do We Measure Success? Is It the Test, the Number of Tests, the Stage, or the Percentage of Screen-Detected Patients? The Permanente Journal Fall 2011; 15 (4): 30-38 